\title{
L'instrumentalisation des Provinces-Unies dans l'iconographie de Versailles*
}

\begin{abstract}
«Notre monarque se divertit à faire bâtir des palais : cela est digne d'un roi. Il y a même une utilité générale; car, par ce moyen, les sujets peuvent prendre part aux plaisirs du prince, et voir avec admiration ce qui n'est pas fait pour eux. Tant de beaux jardins et de somptueux édifices sont à la gloire de leur pays.»
\end{abstract}

Jean de La Fontaine (1621-1695).

Le règne de Louis XIV coïncide avec le Grand Siècle de la France. Après une longue période de troubles religieux et politiques, le royaume retrouve, au XVII $^{e}$ siècle, une stabilité intérieure. Les guerres de Religion (1562-1598) ont, sans doute, été aussi traumatisantes pour les $\mathrm{XVII}^{\mathrm{e}}$ et XVIII ${ }^{\mathrm{e}}$ siècles que la Révolution française a pu l'être pour les XIX ${ }^{e}$ et XX $X^{e}$ siècles. Le rétablissement de la paix et de l'ordre du royaume est donc une réussite majeure.

L'échec de la Fronde (1648-1653) consacre les efforts de modernisation et de centralisation du pouvoir, et le règne personnel du Roi-Soleil (1661-1715) symbolise par excellence la monarchie absolue.

Le jeune roi séducteur et pugnace qui hérite d'un sceptre écorné par la Fronde va faire des premières années de son règne une suite époustouflante de réussites. Guerres pleines de panache, affirmation de l'État, organisation d'un mécénat d'une rare fécondité, mise au pas du clergé, de la noblesse, et du tiers état, les trois « ordres » de la société [...]. Les immenses travaux de Versailles viendront couronner dans une ambiance de fête le triomphe de Louis et de sa monarchie absolue. ${ }^{1}$

* Andreas Nijenhuis prépare actuellement à l'Institut Universitaire Européen de Florence une thèse sur la perception française des Provinces-Unies, 1598-1648, sous la direction de MM. Gérard Delille et Jacques Solé. Il remercie vivement Mme Christine Vicherd de l'université Grenoble II, M. Willem Frijhoff de l'Université Libre d'Amsterdam et M. Roger Chartier de l'EHESS pour leurs remarques critiques respectives.

1. Anne de Margerie et al. (éd.), Versailles an siècle de Lonis XIV, Paris, Textuel, 1993, p. 5.

XVII' siècle, $\mathrm{n}^{\circ} 210,53^{e}$ année, $\mathrm{n}^{\circ} 1-2001$ 
Louis XIV n'aime guère Paris, vraisemblablement à cause des troubles de la Fronde, qui ont entrainé la fuite de la famille royale de la capitale. Aussi décide-t-il, dès 1668 , de s'installer avec la cour à Versailles. À cette fin, il fait remanier profondément le modeste château de chasse de son père, Louis XIII. La décision de s'établir durablement à un endroit fixe tranche avec la tradition multiséculaire de l'itinérance royale. Avec l'installation de la cour en mai 1682, le château de Versailles devient indubitablement le centre de l'État imaginé par Louis XIV : «Versailles tend à devenir le lieu principal du culte monarchique $»^{2}$.

Au sein du palais, la Grande Galerie, construite et décorée entre 1680 et 1684, joue un rôle central : c'est ici que le roi se tient sur son trône d'argent à l'occasion des ambassades extraordinaires; c'est encore ici que se déroulent les grandes fêtes et les cérémonies régaliennes. Salle des pas perdus, la Galerie est également le passage obligé pour se rendre à la messe quotidienne. Les nobles de la cour sont amenés à fréquenter régulièrement la Galerie. En somme, la Grande Galerie est l' «épicentre » de la monarchie louis-quatorzienne, le centre de la vie politique française. «Versailles, tout particulièrement, fut à l'image du monarque qui supervisa sa construction avec un soin si passionné $»^{3}$.

Le sujet principal des tableaux qui ornent la voûte de la Galerie des Glaces est la guerre de Hollande (1672-1678). Cet article cherche à analyser le programme iconographique mis en œuvre dans le saint des saints même de la monarchie française. Le questionnement de l'imagerie royale proposé ici est triple. Quelle est la nature du programme mis en images? Quelle est la fonction de cette série de peintures ? Quel sens révèlent les décorations dans le contexte de l'époque, et plus précisément des relations franco-hollandaises? Il s'agit en définitive de déterminer comment la République des Provinces-Unies est représentée dans l'iconographie de la Galerie des Glaces à Versailles et d'expliquer pourquoi elle occupe une place si importante dans l'affirmation idéologique de la politique royale.

I. LA GRANDE GALERIE: LE CENTRE DE L'UNIVERS DU ROI

La fonction centrale de la Grande Galerie, de dimensions royales, impose un décor digne du roi ${ }^{4}$. En effet, «la galerie des Glaces est construite pour célébrer Louis XIV, vainqueur de l'Europe $»^{5}$.

Le programme iconographique définitif est fixé en 1679, non pas comme d'ordinaire par le surintendant des bâtiments du roi, mais par le Conseil secret du roi

2. Jean-Marie Apostolidès, Le roi-macbine, spectacle et politique an temps de Lonis XIV, Paris, Minuit, 1981, p. 137.

3. Peter Burke, Lonis XIV, les stratégies de la gloire, Paris, Le Seuil, 1995, p. 29.

4. La Grande Galerie, actuellement surtout connue sous le nom de Galerie des Glaces $(73 \mathrm{~m}$ de long, 10,5 m de large et 12,3 m de haut) est construite en 1680, à l'emplacement d'une terrasse entre les appartements de la reine et ceux du roi, par Jules Hardouin-Mansart (1646-1708). La peinture de la voûte est exécutée par Charles Le Brun (1619-1690) entre 1681 et 1684. La Galerie est parmi les parties du château de Versailles qui ont le mieux conservé leur aspect initial, voulu par Louis XIV. Ceci est également vrai pour les peintures, malgré leur encrassement actuel.

5. A. de Margerie, op. cit., p. 11. 


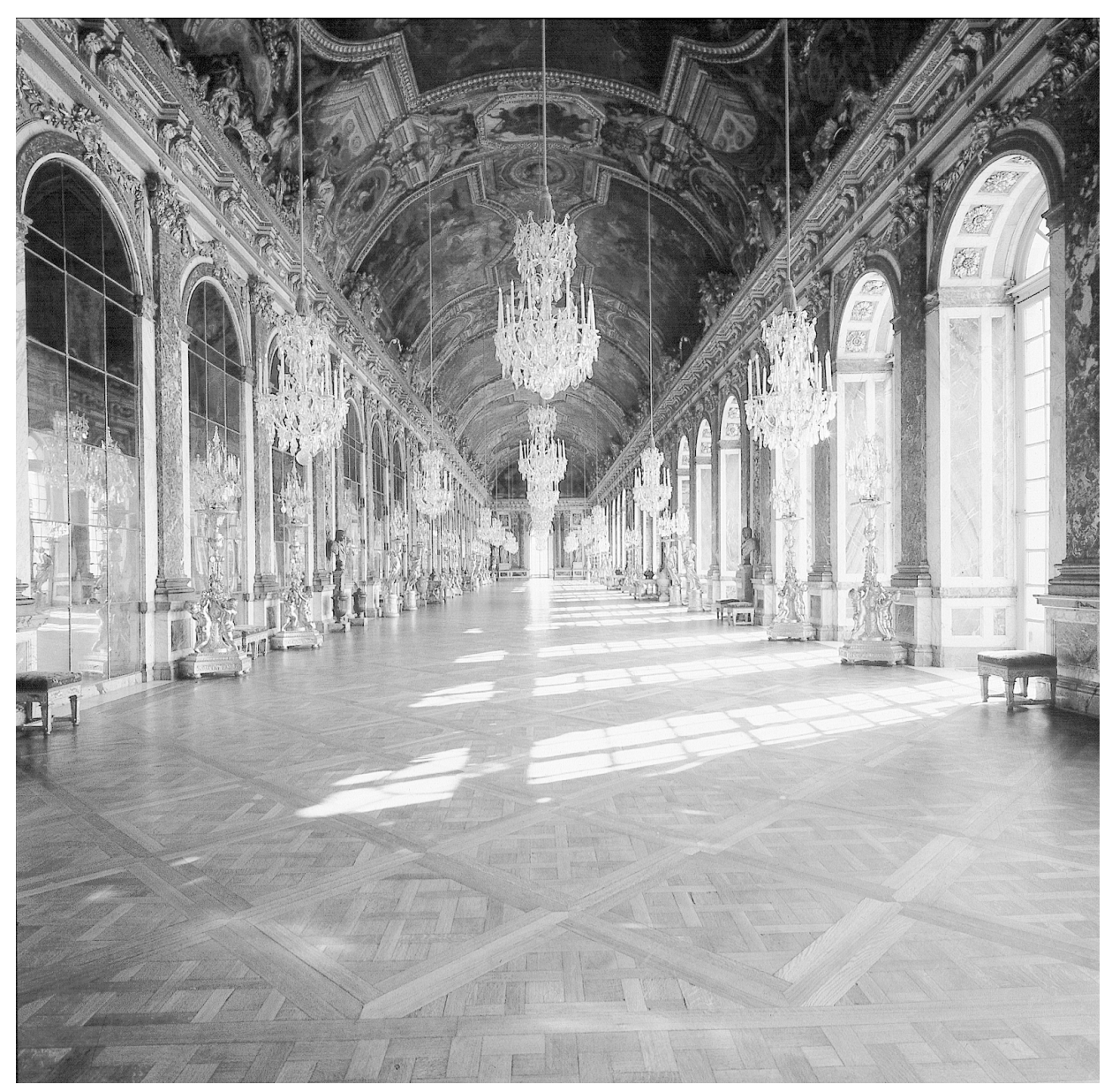

Vue intérieure. Grands appartements :

Galerie des Glaces, vue sur le Salon de la Paix 
même. Initialement, un programme assimilant Louis XIV à Apollon, la personnification du soleil, avait été prévu pour la Galerie des Glaces. Premier peintre du roi, Charles Le Brun a révisé, au cours de 1679, ce programme iconographique en faveur d'une mise en scène d'Hercule, avant que le Conseil secret ne se décide finalement à adopter une iconographie politique explicite, donc très lisible, et non plus à dominante allégorique ou mythique ${ }^{6}$. Ce programme expose ce que doit être une monarchie selon l'idéologie de Louis XIV.

L'omniprésence de la personne royale dans l'iconographie officielle n'implique pas pour autant le complet abandon de l'allégorie. En effet, "grâce au langage de l'allégorie, l'artiste pouvait représenter des événements dont la surface visible était réduite, telle la décision du roi d'assumer personnellement le pouvoir ${ }^{7}$. Cependant, la mise en scène quasi systématique de sa figure propulse le roi au rang des personnages immortels. Le roi côtoie en effet des dieux antiques, des personnages mythologiques, les allégories de notions abstraites (et éternelles, bien que changeantes), ou encore les personnifications de fleuves, de provinces et d'États.

Naturellement, la position centrale du roi n'est pas due au hasard. Le roi doit focaliser l'attention.

Entre tous les caractères, celui de Sa Majesté doit éclater. Il faut louer le Roy partout, mais pour ainsi dire sans louange, par un récit de tout ce qu'on lui a vu faire, dire et penser, qui paraisse désintéressé, mais qui soit vif, piquant, et soutenu, évitant dans les expressions tout ce qui tourne vers le panégyrique. ${ }^{8}$

Voilà ce qui caractérise les efforts "publicitaires» sous Louis XIV. Les mêmes préceptes sont appliqués, par les soins du méthodique Colbert, à la peinture (portraits et tableaux), aux textes littéraires (odes, pièces de théâtre), à la couverture des faits et gestes du roi dans la Gazette et le Mercure Galant (articles d'actualité et numéros spéciaux), ou encore à ce que Louis Marin a appelé, non sans humour, l' « hostie royale : la médaille historique $»$.

La Grande Galerie de Versailles est emblématique de cette pléthore d'éloges. Elle

6. Le Conseil secret du roi, ou Conseil d'en Haut, intervint essentiellement dans les affaires étrangères du royaume et se composa du roi et de quelques ministres seulement, qui étaient en 1678-1679 Michel Le Tellier (1603-1685, chancelier), son fils François Michel de Louvois (1639-1691), Jean-Baptiste Colbert (1619-1683, surintendant des bâtiments du roi) et Arnauld de Pomponne (1618-1699, secrétaire aux Affaires étrangères depuis 1672, remplacé en 1679 par Charles Colbert (ca. 1626-1696), frère de Jean-Baptiste Colbert). Voir à ce propos la thèse de Gérard Sabatier, Versailles ou la figure du roi : essai sur la représentation de la monarchie absolue, Lille, Atelier national de reproduction des thèses, 1998, 516 p., p. 165-197.

7. P. Burke, op. cit., p. 37

8. Fragment d'une lettre de Paul Pellisson (1624-1693), l'un des concepteurs du programme de glorification de Louis XIV, à Colbert, écrite vers 1670, publiée dans P. Pellisson-Fontanier, Euvres diverses, Paris, Didot, 1735, t. 2, p. 323-328, citée par Louis Marin, dans son œuvre dense Le portrait du roi, Paris, Minuit, 1981, p. 47.

9. L. Marin, op. cit., p. 147, titre ; P. Burke, op. cit., p. 209, conclut à un nombre de 322 médailles historiques frappées au cours du règne de Louis XIV et signale l'importante production de ces «hosties royales » dès la prise de pouvoir personnel de Louis XIV (70 médailles pour la décennie 1660-1670, et 67 pour la décennie suivante, contre 26 seulement pour la décennie 1650-1660). 
renferme tous les éléments du programme de glorification royale, dont elle participe, dans un ensemble cohérent. La focalisation sur la figure princière y est notamment du plus bel échantillon ${ }^{10}$.

Bien entendu, le public contemporain de la Galerie fut plutôt restreint, surtout par rapport aux œuvres exposées en public (plus visibles, bien que pas forcément déchiffrables par un public largement analphabète) ou, surtout, imprimées (plus largement diffusées). Cependant, tous les nobles résidant à la cour fréquentaient probablement avec régularité la Galerie. Et il est vrai que la Maison royale «est tous les jours visitée de tout ce qu'il y a de personne en France et que les Étrangers et ceux qui ne peuvent pas avoir le plaisir de la voir sont bien aisés d'en ouïr raconter les merveilles $»^{11}$. En effet, les nouvelles circulent. Des descriptions du palais sont disponibles à Paris et en province pour « donner quelque idée de cet agréable séjour à ceux qui en sont éloignés $»^{12}$.

Mais, soucieux de son image auprès de la descendance, Louis XIV destine sans doute surtout à l'éternité les monuments édifiés à sa gloire. Les fresques, le bronze et la pierre sont des supports de choix pour livrer le message aux générations futures. Lors de la campagne de Flandre en 1667, il s'entoure de peintres (Le Brun luimême suivit le roi). Pendant la guerre de Hollande, des historiographes (dont Racine, auteur des inscriptions de la Grande Galerie) sont invités à suivre l'arrièreban. La nature explicite de l'iconographie du règne y trouve sans doute une explication. "Car on écrit pour la postérité », stipule à ce propos l'un des initiateurs de la glorification systématique du roi, Paul Pellisson ${ }^{13}$.

En résumé, «les décorations [de la Grande Galerie], œuvre de Le Brun et de ses collaborateurs, constituent ce qui est probablement la version la plus mémorable de "l'histoire du roi" " ${ }^{14}$.

\section{Les débuts du règne et le contexte européen}

Située entre le Salon de la Guerre et le Salon de la Paix au premier étage du palais, à proximité des appartements du roi, la Grande Galerie s'ouvre sur le parc par 17 fenêtres répondant à 17 arcades revêtues de glaces ${ }^{15}$. Cette disposition fait que

10. Voir particulièrement G. Sabatier, op. cit.

11. André Félibien, Description sommaire du châtean de Versailles, Paris, Desprez, 1674, rééd. 1696, p. 275, cité dans Louis Marin, op. cit., p. 226.

12. A. Félibien, op. cit., p. 275, cité dans L. Marin, op. cit., p. 226. Le Mercure Galant de décembre 1684 donne une ample description de la Galerie, ainsi que les ouvrages de Pierre Rainssant (ca. 1640-1689, numismate, proche de Colbert), Explication des tableaux de la Galerie de Versailles, Versailles, Muguet, 1686, et de François Charpentier (1620-1702) de l'Académie française, Traité de la peinture parlante, Expli cation des tableaux de la Galerie de Versailles, Paris, Muguet, 1684, publié inachevé.

13. P. Pellisson, op. cit., t. 2, p. 323-328, cité dans L. Marin, op. cit., p. 49: «Car on écrit pour la postérité qui ne les [les acteurs de la Guerre de Hollande] a pas vus; et ce n'est pas même toujours les connaittre que de les voir ».

14. P. Burke, op. cit., p. 92.

15. Cf. L. Marin, op. cit., p. 235 : «La plus ou moins grande proximité de la personne du roi définit le principe d'une hiérarchie». 
seule la voûte comporte des peintures. Les tableaux sont divisés en 12 médaillons relatant les hauts faits du règne, six octogones décrivant le caractère du roi, et 12 grands tableaux traitant essentiellement de la guerre de Hollande.

La voûte retrace en sept travées la vision française officielle de la guerre de Hollande et se lit comme « une somptueuse bande dessinée $»^{16}$. La partie médiane plante le décor de la guerre de Hollande. Deux grands tableaux montrent les débuts du règne personnel de Louis XIV (1661) et le contexte européen, représenté sous la forme d'allégories des pays voisins convoitant la France ${ }^{17}$. Autour des tableaux centraux se trouvent quatre images ovales, représentant des faits administratifs du règne débutant: «L'ordre rétabli dans les finances $(1662) »^{18}$; la «protection accordée aux beaux-arts (1663)»; le « rétablissement de la navigation (1663)»; et la « réformation de la justice (1667) ». Deux tableaux octogonaux ont trait à la guerre de Dévolution (1667-1668).

Ainsi, l'ensemble central met en image l'établissement de l'ordre louis-quatorzien, et les origines politiques de la guerre de Hollande.

\section{L'excellence du règne et la prééminence française en Europe}

Les six octogones au nord et au sud de la scène centrale présentent Louis XIV en figure paternelle, prenant soin de ses sujets. Le « soulagement du peuple pendant la famine (1662) »; « la fureur des duels arrêtée (1667) »; l' " acquisition de Dunkerque (1662) » et l'établissement de la «sûreté dans la ville de Paris (1665)» se rapportent aux actions royales concernant le retour de l'ordre et de la prospérité dans le royaume. Les huit ovales de part et d'autre du tableau central s'attachent, quant à eux, à montrer la prééminence de la royauté française en Europe. Ils montrent la gloire et l'honneur de la France dirigée par Louis XIV. «La Hollande secourue contre l'évêque de Munster (1665) » montre la fidélité du roi à ses alliés ; la « réparation de l'attentat des Corses (1664)» montre ce qui arrive à ceux qui portent atteinte à la France; la «défaite des Turcs en Hongrie par les troupes du roi (1664)» présente Louis XIV comme protecteur et sauveur de la chrétienté ; « la prééminence de la France reconnue par l'Espagne (1662)» établit le rang de la France en Europe ; l' «établissement de l'hôtel des Invalides (1674) » affiche la magnanimité du roi ; le tableau «ambassades envoyées des extrémités de la terre » affirme la reconnaissance de la place de la France dans le monde; le «renouvellement de l'alliance avec les Suisses (1663)» prône la loyauté du régime du Roi-Soleil ; la «jonction des deux mers (1667) » démontre, enfin, les prouesses et la puissance du génie français.

16. G. Sabatier, op. cit., p. 237 , titre.

17. À savoir les Provinces-Unies, l'Espagne et l'Empire, les trois puissances continuellement évoquées dans les peintures de la Galerie. On notera l'absence quasi absolue, à l'exception d'une citation discrète, de l'Angleterre.

18. Les titres sont ceux qui sont indiqués sur la voûte de la Grande Galerie même. En effet, pour exclure toute erreur d'interprétation de la part du spectateur, chaque tableau porte une inscription explicative. 
Les deux séries de représentations énoncent explicitement au spectateur les qualités personnelles du roi et celles de la France sous son règne. En effet, comme le montre le groupe central où le roi assume personnellement les charges du gouvernement, toutes les qualités de la France découlent de celles du roi même. L'iconographie de la Galerie des Glaces comporte en conséquence un message politique explicite.

\section{LA FRANCE ROYALE,}

VAINQUEUR DE LA RÉPUBLIQUE DES PROVINCES-UNIES

Après avoir introduit les débuts du règne personnel de Louis XIV et la position prééminente de son royaume au sein de l'Europe, le programme iconographique de Le Brun fait la démonstration des qualités exposées dans le groupe central et les petites peintures, à savoir le triomphe du roi face à ses ennemis. Les ProvincesUnies sont, en l'occurrence, le référent de prédilection.

En effet, les dix grands tableaux sur la voûte relatent les faits personnels du roi au cours de la guerre de Hollande. Vues d'en bas, il s'agit des représentations les plus aisément lisibles, aussi bien de par leur taille que par la nature explicite des scènes. Effectivement, dans la plupart des cas, le roi figure en personne dans les tableaux, qui portent tous sur des actions identifiables, d'autant qu'un titre précis rafraîchit au besoin la mémoire du spectateur ${ }^{19}$.

\section{La consécration de la primauté française: la guerre de Hollande}

Au-dessus de l'entrée du Salon de la Guerre, une grande scène en arc de cercle offre le spectacle des agissements des ennemis de la France. L' "Alliance de l'Allemagne et de l'Espagne avec la Hollande (1672)» expose trois femmes en désarroi se donnant la main, dans l'ombre du secret : l'Allemagne porte la couronne impériale et est dominée par un aigle à double tête; la Hollande est vêtue en plébéienne, avec par-dessus ses vêtements de femme du peuple un manteau somptueux (allégorie de la République qui, à cause de sa richesse, est devenue prétentieuse) ; l'Espagne enfin est couronnée et porte le collier de la Toison d'or. Elles sont accompagnées de l'aigle impérial et de deux lions, symboles respectifs des puissances en présence. Derrière elles, des personnages préparent de façon chaotique une défense et fabriquent des armes. La Hollande semble paniquée, l'Allemagne et l'Espagne semblent également prises au dépourvu par l'action foudroyante de Louis XIV. L'alliance entre les trois pays se conclut de manière hâtive, dans une atmosphère menaçante et secrète.

19. Promu surintendant des bâtiments royaux à la mort de son rival Colbert (survenue en 1683) Louvois (1639-1691) fit remplacer les titres explicatifs originels du protégé de Colbert François Charpentier (1620-1702), jugés trop grandiloquents, par des textes plus concis, composés par Jean Racine (1639-1699). Ce fut une victoire pour les Modernes que les deux séries d'inscriptions fussent composées en français et non en latin. 
La position au-dessus de l'entrée du Salon de la Guerre indique qu'il s'agit du début de la série de toiles. Selon la même logique, la relation se termine en face, en dessus du passage vers le Salon de la Paix. L'inscription Veni, vidi, vici, visible sur une bannière en marge de la scène de l'alliance contre la France, se réfère directement à Jules César, et assimile Louis XIV au grand stratège antique. Cette référence incontournable donne le ton du programme iconographique développé dans la Galerie.

L'alliance conclue contre la France justifie, avec le rappel de la guerre de Dévolution, « la résolution prise de faire la guerre aux Hollandois (1671) ». La scène montre le roi sur le trône, en cuirasse et manteau fleurdelisé, tête nue, avec devant lui Mars l'invitant dans un char de triomphe, tenu par la Victoire en présence de la Renommée et de Minerve. Aux pieds du roi se distinguent les écussons des villes prises lors de la guerre de Dévolution.

La référence à cette guerre rend légitime la « résolution prise », car la République des Provinces-Unies avait à cette occasion porté préjudice aux intérêts et à l'honneur de la France, en exigeant l'abandon des conquêtes faites au nom de la reine ${ }^{20}$. L'un des autres ovales montre par ailleurs l'aide apportée par Louis XIV aux Hollandais en 1665. Leur attitude dans la guerre de Dévolution témoigne, dans ce contexte, de leur ingratitude. Il est donc juste de punir l'insolente République.

«Le Roi arme sur terre et sur mer (1672)», met en image les préparatifs de la guerre décidée auparavant. Le roi est au centre, en cuirasse, avec derrière lui la Prévoyance (en bleu) et la Vigilance (en blanc). Minerve, au-dessus du roi, vient poser son casque, Mercure en rouge apporte un bouclier. À droite arrive Mars avec des troupes, à l'opposé Neptune conduit des marins. Dans les airs Cérès, l'Abondance, Pluton avec trois chevaux, et Apollon avec sa lyre ${ }^{21}$. En arrière-plan des constructions militaires et navales montrent concrètement les préparatifs de guerre. Dans cette scène agitée, le roi se tient au centre, immobile, décidé, et donne des ordres.

La scène suivante décrit le commencement de la campagne, et notamment la prise de quatre villes stratégiques allemandes détenues par les Provinces-Unies. «Le Roi donne ses ordres pour attaquer en même temps quatre des plus fortes places de la Hollande (1672) », montre un conseil de guerre : le roi se tient, là aussi, au centre, en armure à la romaine. Il est entouré de trois hommes identifiables - ce qui n'est pas le cas dans les autres toiles, où les personnages autour du roi sont allégoriques et mythiques - à savoir Monsieur en bleu, Condé en brun, Turenne en rouge ${ }^{22}$. Le Secret, en

20. Marie-Thérèse d'Autriche (1638-1683, reine de France depuis 1660) était, selon la vision française, susceptible d'hériter à la mort de son père, Philippe IV d’Espagne (1605-1665), des Pays-Bas espagnols, en raison du droit dit de dévolution qui stipule que la succession féminine est possible s'il n'y a pas d'héritier masculin.

21. Pour mémoire : Minerve est la déesse de la sagesse ; Mercure le dieu du commerce et de l'éloquence ; Mars celui de la guerre ; Neptune de la mer ; Cérès est la déesse des moissons ; Pluton gouverne les morts ; Apollon représente le jour, la lumière civilisatrice. La signification des figures allégoriques était communément connue parmi l'élite de l'époque.

22. Monsieur, frère de Louis XIV, Philippe I ${ }^{\text {er }}$ duc d'Orléans (1640-1701, promu duc en 1660) participa à la campagne. Louis II de Condé, dit le Grand Condé (1621-1686), servit pendant les guerres de Trente Ans et de Hollande. Henri de Turenne (1611-1675, maréchal de France dès 1644) avait servi en Hollande sous le commandement de son oncle Frédéric-Henri de Nassau (1584-1647). Revenu en France, il a combattu dans les guerres de Trente Ans, de Dévolution et de Hollande. 
tenue égyptienne, se tient derrière le roi, la Prévoyance est assise à ses pieds, Minerve plane au-dessus de tout ce monde. La carte stratégique déployée derrière le roi porte les noms des quatre places attaquées simultanément (Wesel, Orsoy, Rhinberg, Buricq selon l'inscription) ainsi que celui de Tolhuys, une maison de douane près de Arnhem, où le Rhin est passé à gué.

«Le Passage du Rhin en présence des ennemis (1672) » représente ce dernier événement. Le roi est assis sur un trône d'argent placé sur un char de triomphe, tiré par deux chevaux. Il tient la foudre dans ses mains et passe par-dessus un homme avec un vase, symbole du Rhin. Hercule pousse le char, une Victoire brandit le nom de Tolhuys. Par terre quatre femmes, représentant les villes prises, sont piétinées. Deux hommes apportent les clés de Rees et Emmerick, places fortes prises juste après les quatre cités précédentes. Entre les villes renversées et les hommes approchant, la Hollande, vaincue, se tient debout, se protégeant avec son bouclier, accompagnée de son lion rugissant. Tout ce qui symbolise ses richesses est à ses pieds. Le désordre du commerce est figuré par des paquets de marchandises répandus sur le sol. La ruine de la marine est représentée par un matelot qui tombe et se tient à l'ancre de son navire. Dans le ciel s'envolent la Victoire, des Renommées, ainsi que Mercure. L'Espagne est symbolisée par une femme qui essaie, en vain, de retenir le char victorieux.

La scène assimile le roi à un conquérant classique, comme Alexandre le Grand ou Jules César, qui ne peut être retenu par qui que ce soit. L'image, hyperbolique, exalte le triomphe d'une entrée fulgurante aux Pays-Bas du Nord. L'étape suivante du discours iconographique puise dans le même registre. Il s'agit de la prise de Maastricht, ville fortifiée défendue par les armées des états généraux des Provinces-Unies, que Louis XIV assiège l'année suivant l'invasion des Provinces-Unies. «Le roi prend Maestricht en treize jours (1673)» fait figurer Mars, ôtant le bouclier avec l'inscription «Maestricht» des mains d'une femme affalée, s'inclinant. L'Europe, casquée et vêtue de bleu, regarde, effarée. Elle est tombée de son cheval à la vue de cette démonstration de la force française. Même l'Amérique, sous la forme de deux indigènes américains, observe la scène. Leur présence fait référence à la victoire navale française au large de Tobago ${ }^{23}$.

L'image insiste lourdement sur le siège, réellement très efficace, de la ville de Maastricht - pourtant réputée pour la solidité de sa défense - mené en mai 1673 par Vauban, sous la conduite du roi lui-même. La référence indirecte à la victoire remportée sur la marine néerlandaise devant les côtes américaines insiste, elle, sur la force de la Royale, la marine française créée quasi de néant sous la direction de Colbert et désormais capable de se mesurer avec la marine hollandaise, référence en la matière. En outre, il est ainsi suggéré que l'écho des succès français porte jusqu'en Amérique.

23. La bataille navale de Tobago (1677) se déroula au large de cette île antillaise, colonisée dès 1628 par la Compagnie des Indes occidentales (ou WIC pour West Indische Compagnie, fondée en 1621). La bataille, qui opposa l'amiral d'Estrée au commandeur Binckes fut particulièrement meurtrière : l'on compta plus de 2000 morts, mais un débarquement de troupes françaises sur les côtes de Tobago put être évité, ce qui fait que la bataille est qualifiée d'indécise dans les annales néerlandaises. Cependant, un débarquement français réussit quelques mois plus tard, ce qui mit fin à la colonisation néerlandaise de la «Nouvelle Walcheren». 
Dans l'octogone central «la paix conclue à Aix-la-Chapelle (1668)», une femme assise par terre, éplorée, faisait référence à la Franche-Comté, conquise lors de la «Guerre contre l'Espagne pour les droits de la Reine (1667)» et rendue à l'Espagne en vertu du traité de paix d'Aix-la-Chapelle. Le tableau «La Franche-Comté conquise pour la seconde fois (1674)» revient sur cette scène introductive. Le roi y figure classiquement en cuirasse romaine, cette seule fois coiffé de son casque, contemplant l'activité de Mars qui traîne à ses pieds les villes conquises. La FrancheComté git au sol et tend les clés de la province. Quatre boucliers, avec les écussons de Besançon, Dôle, Gray et Vesoul, sont amenés au roi. En arrière-plan, Hercule et Minerve gravissent un rocher pour combattre un homme armé, qui représente la citadelle de Besançon prise d'assaut après un siège difficile. Sur un arbre l'on distingue un aigle effrayé, symbole de l'Empire, intervenu en faveur du duc de Lorraine et battu par Turenne le 16 juin 1674. En dessous de l'aigle impérial un Suisse en armes se retire, décidant de ne pas intervenir. De l'autre côté de la scène, une Victoire dresse des trophées, tenant deux couronnes de laurier symbolisant sans doute les deux conquêtes de cette même province. Sur des nuages au-dessus du roi l'on reconnaît la Renommée et la Gloire.

Tout respire le triomphe inexorable du roi et la justesse de ses actions glorieuses, mais la scène est plus agitée que les autres représentations des hauts faits de la guerre de Hollande. Ainsi, la "Prise de la ville et citadelle de Gand en six jours (1678)» montre une conquête plus rapide. Le roi est assis sur une aile de l'aigle de Jupiter, avec la foudre à la main. Des cieux, entouré du Secret et de la Vigilance, il contemple Minerve qui arrache soudainement l'étendard et la clé de la ville de Gand, incarnée par une femme en blanc avec un manteau bleu.

Une fois de plus, le roi est présent en personne dans le tableau, pour rappeler que les actions de la France sont les siennes. La scène accolée à celle de la prise de Gand fait état des conséquences de l'action célébrée précédemment. L'œuvre intitulée «mesures des Espagnols rompues par la prise de Gand» démontre le trouble que le Roi-Soleil sème dans le camp adverse. L'on y voit l'état de l'Espagne lorsque la Renommée claironne la chute de Gand. La surprise et la stupeur règnent. La Politique est renversée, son lion est assommé, son léopard est mis en fuite. Ni la force (le lion), ni la finesse (le léopard) ne peuvent être d'aucun recours à cette Politique, dont un genou s'appuie sur un livre ouvert où l'on peut lire le nom de Machiavel ${ }^{24}$.

24. C'est un détail saillant que le seul nom propre (on peut lire «Hist. di Machiavelli ») à figurer dans toutes les représentations de la Galerie soit celui du penseur politique florentin Nicolas Machiavel (1469-1527), ici synonyme d’une politique abjecte. Le Prince (écrit en 1513, publié en 1531) est plus souvent cité comme livre de la tyrannie, les Histoires florentines (écrites entre 1512 et 1526, éditées dès 1532), en l'occurrence tenues pour responsables de la politique antifrançaise de l'Espagne, ne sont, quant à elles, que rarement accablées. Dans le chapitre XVI du Prince, Machiavel évoque bien le lion et le renard comme symboles respectifs de la force et de la ruse, mais non pas le lion et le léopard. La référence à Machiavel, imprécise quant à son contenu, semble donc uniquement symboliser une politique méprisable, «machiavélique ». Louis XIV lui-même n’échappe pas à ce mécanisme : en 1674, un pamphlet dénonce sa politique et appelle le roi Machiavellus gallicus (voir P. Burke, op. cit., p. 135, à propos de ce pamphlet, et Christiane Frémont et Henry Méchoulan (éd.), L'anti-macbiavélisme de la Renaissance aux Lumières, Paris, Association pour la revue Corpus, 1997, 253 p., pour la longue carrière d'antimodèle de Nicolas Machiavel). 
Le Conseil (en rouge, avec la main sur les yeux) et la Prévoyance (à genoux, en blanc) ne se portent guère mieux. Ils sont déconcertés, tout comme quatre soldats qui s'enfuient à droite sous l'effet des foudres divines.

La même déconfiture transparaît dans l'image finale de cette série de tableaux. «La Hollande accepte la paix et se détache de l'Allemagne et de l'Espagne (1678)», situé en dessus de l'entrée du Salon de la Paix, reprend la composition de l'Alliance des trois puissances ennemies, qui se trouve à l'autre extrémité de la Galerie des Glaces. Sur un podium se tient donc l'Allemagne impériale avec son aigle, regardant la Paix avec étonnement; sur la seconde marche du podium il y a l'Espagne, avec son lion renversé ; en bas se trouve la Hollande. Cette dernière s'en va, bien que l'aigle tente de la retenir. Son lion s'efforce de tenir ensemble les sept flèches symbolisant ses sept provinces. À droite, l'Angleterre, couronnée, dotée d'un sceptre et accompagnée d'un paon (signe d'orgueil et de vanité), offre des vaisseaux et des troupes à la Hollande pour éviter qu'elle accepte la paix offerte. Mais le stratagème des ennemis échoue, car la Hollande accepte la paix généreusement offerte par la France.

Le cycle est terminé : la Paix se fait, pour les puissances ennemies, dans le même désarroi et dans le même désordre que l'Alliance contre la France s'était conclue dans le premier tableau de la série. Le contraste entre la tranquillité du roi et la détermination de la France, d'une part, et la précipitation, la peur et la lâcheté des ennemis, d'autre part, est saisissant. Tout comme les glaces et les marbres employés dans la Galerie sont destinés à la promotion des corps de métiers du royaume, les images de la voûte sont appelées à chanter les louanges et le triomphe de la «tête pensante » de la France, le Roi-Soleil ${ }^{25}$.

\section{L'apothéose du roi et de la France}

Comme on l'a vu, le sens des peintures varie selon leur type (ovales, octogonales, grands tableaux) et leur emplacement. L'ensemble du milieu, composé de deux grands tableaux, de quatre ovales et de deux octogones, introduit le règne et son contexte européen, en préalable au thème principal de la voûte, la guerre de Hollande. Le caractère patriarcal du roi, sa bonté envers ses sujets sont développés dans les octogones de part et d'autre du centre de la Galerie. Les ovales montrent la prééminence et la puissance de la France, établies sous l'égide de Louis le Grand. Les peintures murales sont donc, en fonction de leur type et de leur emplacement, porteuses d'un message spécifique. L'ensemble des représentations s'efforce de montrer explicitement les qualités du roi, la situation enviable - et effectivement convoitée - de la France et la puissance triomphale de celle-ci dans le cas particulier de la guerre de Hollande.

La personne du roi est prééminente au sein des représentations de la Galerie des Glaces. Dans sept grands tableaux sur les douze (comprenant les deux au-dessus des passages vers les Salons de la Guerre et de la Paix), Louis XIV figure au centre. Il est

25. Charles Le Brun 1619-1690, Le décor de l'escalier des Ambassadeurs à Versailles, Paris, Éditions de la Réunion des musées nationaux, 1990, p. 24 : « On dit que cette illustre galerie était à la fois un encouragement pour l'industrie française et une sorte de réclame permanente». 
à chaque fois aisément identifiable, aussi bien par la noblesse de ses traits que par les signes royaux dont il est revêtu. Dans la fièvre de l'action, Louis le Grand se tient toujours immobile, serein, maitrisant la situation et donnant des ordres. Il commande toute l'action qui se déroule sur la voûte.

Le rang du roi est confirmé dans le seul tableau où d'autres personnages identifiables figurent ( «Le roi donne ses ordres pour attaquer en même temps quatre des plus fortes places de la Hollande (1672) »). Le roi occupe le centre de la scène, où il désigne des places fortes sur une carte des Provinces-Unies. Il s'adresse directement à Monsieur et à Condé, qui se trouvent à sa droite. Monsieur est debout sur l'estrade où se trouve le roi son frère. Monsieur remporta la bataille du mont Cassel sur Guillaume III d'Orange en 1677. Ce fait était célébré dans l'escalier des Ambassadeurs, tandis que dans la Galerie seule une inscription en marge d'un tableau rappelle cette victoire. Le prince de Condé, également de sang royal, est placé du même côté que Monsieur et le roi, mais il n'a qu'un seul pied sur l'estrade, l'autre s'appuie sur la marche inférieure. Turenne, qui n'est pas de sang royal, se trouve de l'autre côté de la scène. Le regard royal n'est pas tourné vers lui et ses deux pieds sont sur la marche inférieure de l'estrade. Son manteau rouge le rapproche d'un simple centurion romain. Les rapports hiérarchiques sont précisément identifiés, chaque personnage a sa place par rapport au roi en fonction de son rang. L'agencement de la scène montre que ces chefs de guerre, aussi brillants soient-ils individuellement, ne sont que des exécutants de la volonté royale.

La France, elle, est au centre d'une autre grande scène de la Galerie. Elle y est revêtue de signes distinctifs propres à la royauté. Son manteau bleu est dûment fleurdelisé, et elle porte une couronne et le sceptre royal. Son apparition est limitée aux scènes générales, qui situent l'action royale dans son contexte européen ( «Faste des puissances voisines de la France »). Dans les Salons de la Guerre et de la Paix de part et d'autre de la Galerie, elle apparaît dans les mêmes conditions : elle est au milieu, dans la coupole, et y symbolise respectivement sa générosité dans la paix et sa force dans la guerre. Autour d'elle, dans les voussures, les trois nations en jeu dans la guerre de Hollande jouissent de la paix ou bien, au contraire, souffrent des conséquences de la guerre.

Dans un seul tableau le roi et la France apparaissent côte à côte. «Le roi gouverne par lui-même (1661) » montre effectivement Louis XIV sur son trône, se détournant des plaisirs personnifiés par les angelots se trouvant à ses pieds pour contempler la couronne tendue par la Gloire. Il est accompagné d'une France sereine et visiblement heureuse. Dans cette scène, qui est la première du cycle des grands tableaux relatant la guerre de Hollande, le roi porte le manteau bleu parsemé de fleurs de lys qui constitue par la suite le signe distinctif du personnage représentant la France. L'action de la France s'apparente sans ambiguité à celle de son monarque. En quelque sorte, elle est le prolongement des actes royaux. Le roi et la France constituent une unité duale, identifiée par la cohérence des compositions (le roi et la France sont toujours au centre) et des attributs (les signes régaliens sont chaque fois les mêmes).

Le contenu politique des tableaux de Le Brun est précis : le règne personnel de Louis XIV comble ses sujets et propulse le royaume à une place prééminente au sein de l'Europe. Et rien ne peut résister à la force herculéenne de la France menée par le roi, comme le montre spécifiquement la guerre de Hollande. 


\section{Les Provinces-Unies ou l'orgueil vaincu}

La cohérence du programme iconographique augmente la lisibilité du message dont il est porteur. Tout le cycle vise à démontrer la splendeur de la France sous la direction royale de Louis le Grand. L'affirmation est faite de deux façons: le programme insiste d'une part sur les qualités du roi et de son gouvernement, et situe d'autre part le royaume par rapport aux autres puissances en Europe, et notamment par rapport aux Provinces-Unies dans le cadre de la guerre de Hollande. Cette double démarche (exposer ses qualités, puis se démarquer des autres nations) a toujours pour finalité d'établir la supériorité de la France louis-quatorzienne. Par conséquent, il est nécessaire non seulement de démontrer sa propre supériorité, mais également d'insister sur l'infériorité de l'autre. La nation qui, dans cette perspective, sert d'étalon, de standard de mesure est la République des Provinces-Unies.

Il est vrai que ce pays - propulsé parmi les grandes puissances européennes lors de sa Révolte contre la tutelle espagnole - fascine les cercles du pouvoir français. Un diplomate au service de Louis XIV résume en 1697 ainsi les choses :

Rien ne saurait être comparé a ce que les Hollandois ont fait par le moyen du commerce et ce sera toujours un sujet d'Étonnement, qu'une poignée de Marchands refugiez dans un petit pays, qui ne produisoit pas a beaucoup de quoy nourir ses nouveaux habitans, ayent abatu la puissance enorme de la monarchie d'Espagne, l'ayant obligé a leur demander la paix et ayant fondé un État qui depuis ce temps la fait l'Équilibre entre les Puissances de l'Europe et qui est en quelque façon l'arbitre de la paix et de la guerre. ${ }^{26}$

Sous la direction de Colbert et avec un succès variable, l'exemple économique néerlandais est appliqué à la France dans le but d'affecter le commerce des Provinces-Unies, que leur esprit bourgeois et républicain rend méprisables. Dans ce but, le gouvernement français s'efforce de favoriser l'industrie et le commerce afin de faire concurrence aux Hollandais. L'attrait pour le modèle économique néerlandais va donc de pair avec une répulsion pour l'organisation politique de la République.

La première évocation de la République dans le cycle des grandes peintures murales a lieu dans la scène préalable, intitulée le «Faste des puissances voisines de la France ». La République y est présente aux côtés de l'Empire et de l'Espagne. La mise en scène est sensiblement identique à celles de l' "Alliance de l'Allemagne et de l'Espagne avec la Hollande (1672)» et de «La Hollande accepte la paix et se détache de l'Allemagne et de l'Espagne (1678)», situées de part et d'autre de la Galerie. L'Empire est assis en haut de l'estrade, l'Espagne au niveau intermédiaire et la Hollande au niveau inférieur. Bien sûr, cette disposition n'est pas innocente.

26. Archives du ministère des Affaires étrangères, Mémoires et documents, Hollande 49 (1697), fo $7-7 v^{\circ}$. 
Elle traduit le rang des nations. La République se trouve naturellement au niveau inférieur, car son organisation politique va à l'encontre de l'ordre naturel, voire divin.

Le rôle modeste imparti à la République de par son essence est souligné par les attributs du personnage qui la représente. Il s'agit d'une femme plébéienne, flanquée du lion néerlandais, qui porte des vêtements simples. Cependant, par-dessus les habits populaires, elle revêt un manteau très richement orné. Ce détail n'est pas dépourvu de sens: tout le caractère d'une République devenue riche, puissante et prétentieuse s'y trouve résumé. Des livres de comptes, des marchandises et le trident de Neptune (le commerce des Provinces-Unies est essentiellement maritime) renforcent cette image d'un pays incarnant des valeurs méprisables au regard des standards aristocratiques français.

Mise en scène dans quatre des douze grandes images de la Galerie des Glaces, la Hollande est à chaque fois présentée de la même façon ${ }^{27}$. En outre, elle figure dans les Salons de la Paix et de la Guerre. Sa présence est moins visible dans deux autres grands tableaux. Dans «Le roi donne ses ordres pour attaquer en même temps quatre des plus fortes places de la Hollande (1672)», une carte militaire désignée par le roi évoque le pays attaqué par les foudres divines. La carte avec les villes rappelle que pendant la Révolte des Pays-Bas du Nord (1568-1648) la principale activité militaire, de la part des Espagnols comme des Hollandais, consistait en de multiples sièges. La fortification des places a par conséquent été élevée en art aux Pays-Bas du Nord. Attaquer simultanément quatre villes fortifiées relève donc, dans ce contexte, de la démonstration d'une force herculéenne. «Le roi prend Maestricht en treize jours (1673) » souligne encore la force française, d'autant que les ouvrages de cette ville jouissaient d'une grande réputation. La ville se retrouve dans la composition de Le Brun incarnée par une femme à genoux, renversée, levant son bouclier dans l'espoir inutile de se protéger contre Mars. Ces deux fresques, ainsi que celle sur la prise de Gand, s'inscrivent dans la tradition des pièces de propagande comme $\mathrm{La}$ Reddition de Breda, exemple célèbre de la glorification d'un siège, peinte en 1635 par Vélasquez (1599-1660).

«Le Passage du Rhin en présence des ennemis (1672)» concentre à lui seul l'essence de toute la guerre de Hollande, vue par Le Brun. La Hollande est subjuguée par le déferlement de la force française. Le char de triomphe conduit par Louis XIV à travers le Rhin fond inexorablement sur elle. Ambition, Arrogance et Orgueil sont par terre, à ses pieds. Louis XIV a eu raison de la République dont l'ingratitude était rappelée par les événements de 1665 et de la guerre de Dévolution ${ }^{28}$.

27. Dans un ordre chronologique, il s'agit de: «Faste des puissances voisines de la France», «Alliance de l'Allemagne et de l'Espagne avec la Hollande (1672)», «Le Passage du Rhin en présence des ennemis (1672)», «La Hollande accepte la paix et se détache de l'Allemagne et de l'Espagne (1678)».

28. «La Hollande secourue contre l'évêque de Munster (1665)» rappelle, effectivement, la fidélité du roi à l'égard de ses alliés. Les deux octogones centraux montrent la guerre de Dévolution, au cours de laquelle l'ingrate Hollande avait frustré les revendications de Louis XIV à propos des droits de sa femme sur les Pays-Bas du Sud. 
La représentation des Provinces-Unies dans le cycle de tableaux se caractérise par sa constance. Premièrement, le personnage symbolisant le pays se trouve systématiquement en bas de la composition pour souligner que sa constitution politique est inférieure à celle de la France et des autres puissances européennes. Ensuite, la puissance ennemie est systématiquement identifiée par les mêmes attributs. Ceux-ci insistent sur le caractère populaire du pays (c'est une République) et sur ses richesses mercantiles (source de son orgueil et de ses prétentions politiques). Finalement, sa position défensive, tantôt paniquée (comme dans la scène de l'Alliance) tantôt dépassée (comme lors du passage du Rhin), confirme l'infériorité de fait de la République des Provinces-Unies par rapport à la France. L'orgueilleuse République est vaincue.

\section{LES PROVINCES-UNIES, LA GRANDE GALERIE ET LE CONTEXTE POLITIQUE}

C'est avec verve que le premier peintre du roi a mis en images un programme politique explicite. L'importance de ce programme iconographique explique la place centrale qu'il occupe au sein du château de Versailles et au sein de l'iconographie royale. La préoccupation quasi obsessionnelle de glorifier la guerre de Hollande dans l'imagerie officielle est par ailleurs perceptible dans d'autres réalisations royales de cette époque. Les réfectoires de l'hôtel des Invalides, dont la fondation est rappelée dans la Galerie des Glaces, participent d'un plan tout à fait analogue à celui de Versailles.

Dans l'hôtel des Invalides, l'actuel musée de l'Armée, quatre salles sont consacrées à la guerre de Hollande ${ }^{29}$. Il s'agit des réfectoires transformés aujourd'hui en salles d'exposition. Elles se situent de part et d'autre de la grande cour d'honneur. À l'est, les salles Turenne et Vauban, décorées par Jacques-Antoine Friquet de Vauroze (1648-1716), magnifient les prises d'Emmerich, Rhinberg, Wesel, Rees, Zutphen et Utrecht. De l'autre côté de la cour, à l'ouest, la salle Henri IV, peinte par Michel II Corneille (1642-1708), relate les sièges de Maastricht, de Dinan, de Huy et de Limbourg. La bataille de Seneffe et la levée du siège d'Oudenaarde y sont également représentées. Les fresques de la quatrième salle, la salle François $\mathrm{I}^{\text {er }}$, qui sont de la main de Joseph Parrocel (1646-1704), rappellent essentiellement des épisodes de la fin de la guerre de Hollande, notamment les sièges de Valenciennes, de Cambrai, de Maastricht et de Gand, ainsi que la bataille du mont Cassel $(1677)^{30}$. Toutes ces scènes rendent compte des actions de Louis XIV. La figure du roi est

29. L'hôtel des Invalides, édifié sur ordre de Louis XIV pour les soldats rendus infirmes par la guerre, fut bâti dès 1670 sur les plans de l'architecte Libéral Bruant (1635-1697). Le dôme et la chapelle Saint-Louis, ajoutés ultérieurement, furent dessinés par Jules-Hardouin Mansart (1646-1708). L’Hôtel accueillit en pension 1500 soldats blessés ou âgés. Le roi anglais Charles II imita l'exemple de Louis XIV avec l'édification, dès 1681, du plus modeste Chelsea Hospital sur la rive gauche de la Tamise (P. Burke, op. cit., p. 172).

30. Les noms des salles sont ceux employés actuellement par le musée des Armées. Le quatrième réfectoire (côté ouest), l'actuelle salle François I ${ }^{\mathrm{er}}$, fut à l'origine orné de fresques dues à Parrocel, mais, rapidement détériorées, elles furent repeintes dès 1706. 
au cœur de deux autres scènes. Tantôt il donne des ordres aux troupes (le roi terrible en guerre), tantôt il reçoit les remerciements des ambassadeurs de l'Empire, de l'Espagne et de la République pour la paix de Nimègue (le roi magnanime en temps de paix).

Ce qui est représenté dans les peintures de Versailles et de l'hôtel des Invalides est repris dans la pierre et le bronze de la porte Saint-Denis et de la statue de Louis XIV sur la place des Victoires.

La porte Saint-Denis, édifiée dès 1672, est de la main de François Blondel (1618-1686). Elle célèbre le passage du Rhin et la prise de Maastricht. Il s'agit ici d'un arc de triomphe sur le modèle romain, destiné à immortaliser un acte glorieux. Il était certes habituel d'élever des arcs temporaires à l'occasion des «joyeuses entrées ", comme celle de Louis XIV et Marie-Thérèse nouvellement mariés à Saint-Jean-de-Luz, mais il s'agissait là de constructions temporaires. Louis XIV ne se contente pas d'imiter les Anciens, il les surpasse par la taille des arcs de triomphe édifiés en son honneur. L'heure est à l'exaltation des capacités militaires de Louis XIV. Tel un nouvel Alexandre le Grand, Louis le Grand « diebus vix sexaginta rhenum wahalium mosam isalam superavit, subegit provincias tres, cepit urbes munitas quadraginta $»^{31}$.

La statue en bronze de la place des Victoires, inaugurée en 1686, était une œuvre de Desjardins (1640-1694), un des sculpteurs qui contribua à la décoration des jardins de Versailles ${ }^{32}$. De taille gigantesque, elle montrait le roi debout, piétinant Cerbère, le gardien antique des Enfers. Une Victoire dûment ailée s'apprête à le couronner de lauriers. Le piédestal était orné de quatre nations vaincues et de bas-reliefs rapportant les hauts faits du règne. L'ensemble était dédié au viro immortali, à l'homme immortel qu'était le roi. Envoyée à la fonte en 1790, la statue n'a survécu au roi que de 75 ans. Les bas-reliefs et les statues des nations vaincues ont, eux, échappé à la fonte et sont actuellement exposés au musée du Louvre.

Toutes ces décorations et tous ces édifices tendent à démontrer la grandeur du royaume de Louis XIV, «magnus inter reges $»^{33}$.

31. «Louis le Grand a, en soixante jours, franchi le Rhin, le Waal, la Meuse et l'Elbe, conquis trois provinces et enlevé 40 places fortes ». Cet arc de triomphe, élevé au frais de la ville de Paris, est orné de bas-reliefs taillés par Michel Anguier (1614-1686). À proximité, une deuxième porte fut élevée dès 1674 pour fêter les succès français. La porte Saint-Martin est l'œuvre de Pierre Bullet (1639-1716), disciple de Blondel, qui employa nombre de sculpteurs ayant participé à la décoration des jardins de Versailles, tels Martin Desjardins (1640-1694) et Pierre Legros (1629-1714), pour la réalisation des bas-reliefs. Ils représentent la prise de Besançon, la rupture de la Triple-Alliance, la prise de Limbourg par les Français et la défaite des troupes "germanorum hispanorum batavorumque » de la Triple-Alliance.

32. Martin Van den Bogaert, dit Desjardins (1640-1694), sculpteur français d'origine néerlandaise. Son nom néerlandais, qui signifie littéralement «Du Verger» fut francisé en «Desjardins ». Il fut l'auteur de plusieurs sculptures des jardins de Versailles, notamment de Diane, la divinité de la nature, et de Thétis, nymphe marine issue de Nérée.

33. «Le plus grand parmi les rois », inscription sur le socle de la statue équestre de Louis XIV sur la place de Notre-Dame des Victoires à Paris. La statue actuellement en place de François Joseph Bosio (1768-1845), érigée en 1822, s’inspire des statues équestres édifiées au cours de la statuomanie glorifiante des années 1680. Cette statuomanie est à rapprocher de l'habitude romaine d'élever une statue de l'empereur dans chaque ville importante. 
La limpidité de l'imagerie royale, telle qu'elle est mise en œuvre en ces différentes expressions, est caractéristique de la période qui suit la guerre de Hollande. Comme le souligne Gérard Sabatier,

la renonciation aux programmes mythologiques et le choix de représenter les actions du roi s'inscrivent d'une façon plus générale dans le courant « historiciste » de l'encomiastique louis-quatorzienne, qui l'emporte dans les dernières années de la guerre de Hollande. ${ }^{34}$

Cependant, même si le réalisme dans l'exécution triomphe sur la mythologie et l'allégorie dans ces œuvres élogieuses, celles-ci n’en relèvent pas moins de l'imaginaire royal. Il est donc temps de revenir à la réalité et de confronter le contenu du cycle de Le Brun au contexte réel de la guerre de Hollande.

\section{Le leitmotiv de la politique française : l'expansion vers le nord}

Les plaines du nord de la France constituent une voie d'invasion redoutable. Aucune barrière naturelle n'arrête l'ennemi, comme c'est le cas à l'est avec les Alpes, au sud avec les Pyrénées et à l'ouest avec l'Atlantique. L'importance stratégique des Pays-Bas espagnols explique par conséquent la politique française d'expansion. La sauvegarde des frontières du nord est certainement d'un intérêt vital pour la France, et elle s'opère par l'extension et la fortification du territoire. Le paysage français conserve d'ailleurs toujours de multiples traces de l'œuvre de Vauban ${ }^{35}$.

Cette politique française a tout pour inquiéter la République des Provinces-Unies. Depuis le début de la Révolte néerlandaise contre l'Espagne (1568-1648), elle est un allié logique de la France : l'affrontement d'un ennemi commun rapproche les deux pays. Cependant, avec la fin des hostilités à l'occasion de la paix de Westphalie et l'avènement en France des idées colbertistes de lutte économique, les relations entre les deux puissances se détériorent. En effet, «la politique anti-hollandaise devait constituer naturellement un trait fondamental du règne personnel [de Louis XIV] qui commençait; elle s'alliait admirablement avec une tentative un peu naïve pour "hollandifier" l'économie française $»^{36}$.

34. G. Sabatier, op. cit., p. 197.

35. Sébastien Le Prestre de Vauban (1633-1707), commissaire général des fortifications dès 1678 remania les fortifications de plus de 300 places et éleva près de 40 nouvelles places fortes, dont un nombre considérable se trouve au nord du pays. De par ses compétences dans le domaine des fortifications, Vauban fut également un redoutable poliorcète. Il dirigea avec efficacité plus de 50 sièges, dont celui de Maastricht (mai 1673).

36. Pierre Goubert, Louis XIV et vingt millions de Français, Paris, 1966, p. 52. Goubert attire à juste titre l'attention sur le mélange d'attrait et de répulsion qui marqua la politique française à l'égard des Provinces-Unies. 


\section{L'imaginaire royal et la guerre de Hollande}

En avril 1662, un traité défensif est conclu entre la France et la Hollande. En vertu de ce traité, une intervention française est sollicitée en 1665, lorsque la deuxième guerre anglo-hollandaise (1665-1667) éclate. Charles II (1630-1685, roi d'Angleterre depuis 1660) cherche à déstabiliser le régime républicain de Jean De Witt, partisan d'une alliance continentale, en faveur de son cousin Guillaume III d'Orange, promoteur d'une politique antifrançaise ${ }^{37}$. L'Angleterre s'allie au cours de cette guerre à l'évêque de Munster qui envahit l'est du pays.

Dans le cycle versaillais, l'ovale «La Hollande secourue contre l'évêque de Munster (1665)» insiste sur ces événements, afin de montrer la loyauté de Louis XIV à l'égard de ses alliés. En réalité, le roi a repoussé le plus longtemps possible l'intervention militaire. Vers la fin de l'année 1665, une petite armée est envoyée aux Pays-Bas du Nord et l'évêque de Munster abandonne ses actions belliqueuses. En réalité, il s'agit ici d'un événement d'une importance politique mineure, moins connu que les autres faits d'armes qu'évoquent les peintures de la Galerie. Il existe donc un décalage entre ce qui est dépeint et la réalité. Mais le contrôle royal des organes de presse évitait la libre circulation des nouvelles désagréables à la Couronne. À titre d'exemple, l'unique journal régulier de l'époque, $L a$ Gazette, est assimilé à un journal officiel, voire de propagande, par les historiens du journalisme ${ }^{38}$. Partant, la disparité entre la mise en scène de Le Brun et la réalité peut sembler moins flagrante. Du moins, la représentation nous présente une « réalité sélective».

L'étape suivante de la «bande dessinée » corrobore ce principe. Les deux octogones concernant la guerre de Dévolution (1667-1668) ne montrent que la justesse des motifs français (la défense des droits de la reine) et l'injustice qu'implique par conséquent la paix signée à Aix-la-Chapelle (la restitution de la Franche-Comté). Le caractère arbitraire de la mise en scène apparaitt clairement dans le compte rendu de la rétrocession de la Franche-Comté. La figure allégorique de la Franche-Comté semble inconsolable du fait de devoir quitter la France. Il s'agit là, détail saillant, d'une contradiction avec une autre scène de la Galerie. Car l'orchestration d'heureuses retrouvailles aurait dans ce contexte été logique. Il n'en est pourtant rien. En effet, «La Franche-Comté conquise pour la seconde fois (1674)» montre la violence

37. Jean De Witt (1625-1672) fut la personne emblématique de l'essor de la bourgeoisie commerçante et républicaine aux Provinces-Unies. Pensionnaire de Hollande depuis 1653, il favorisa l'expansion maritime de la République aux dépens de son rôle militaire sur le continent. Pour cela, il poursuivit une politique d'alliance avec la France, afin de s'assurer de cette puissance continentale. À ce titre, il entra en conflit avec la faction orangiste, menée par Guillaume III d'Orange-Nassau (1650-1702). Guillaume III, fils posthume de Guillaume II de Nassau et d'Henriette Stuart, prétendit effectivement à un rôle militaire plus important de la République en Europe, ce qui l'opposa aux ambitions de la France sous Louis XIV.

38. Voir par exemple l'inusable Raymond Manevy, La presse française de Renaudot à Rochefort, Paris, 1958, p. 14-16, ou Stéphane Haffemayer, «Les gazettes de l'Ancien Régime: approche quantitative pour l'analyse d'un "espace de l'information" ", dans Histoire \& mesure, 1997, no 12 (1-2), p. 69-91. 
des combats. La forte résistance rencontrée lors de la campagne de 1674 était trop bien connue pour permettre de tels propos.

Le programme iconographique s'éloigne de la réalité et se permet des libertés avec le déroulement historique de ce qui est représenté. Toute représentation implique certes un choix restrictif, mais ce choix ne fait pas nécessairement violence à la vérité. Deux artifices de narration dominent donc l'imagerie de la Galerie. D’une part, les tableaux n'évoquent que certains aspects des événements, subtilement choisis pour la plus grande gloire du roi, de l'autre, ils cherchent avec sophistication à duper le spectateur.

La scène du passage du Rhin est révélatrice des deux techniques de propagande mises en œuvre. Bien sûr, l'invasion des Provinces-Unies semble un succès éclatant, surtout si l'on compare la rapidité de la progression des armées françaises à la lenteur des avancées des belligérants pendant la Révolte (1568-1648). Or, les conditions ne sont pas les mêmes. Les armées espagnoles et néerlandaises alors en présence ne peuvent pas soutenir la comparaison avec l'armée, bien plus importante, qu'emploie Louis XIV. Les places fortes néerlandaises, quant à elles, avaient souffert de la réduction des ressources consacrées à leur défense à la suite de la signature de la paix de Westphalie. Leur état ne permettait pas de résister à une attaque surprise.

La splendeur de la victoire ternit encore si l'on rappelle en outre les conditions des débuts de la guerre de Hollande. Les forces des états généraux - quelques escadrons de cavalerie et un régiment d'infanterie - ne se sont que faiblement opposées à l'armée française de 120000 hommes. La «présence de l'ennemi» mise en avant à Versailles comme sur la statue équestre de la place des Victoires a surtout une valeur rhétorique. Le passage du Rhin ne constitue donc nullement un fait militaire majeur. L'importance de l'événement se situe sur un plan symbolique, exploité avec habileté à Versailles.

La vocation du tableau est d'ailleurs avant tout de passer sous silence l'échec qui a immédiatement suivi le franchissement du Rhin. Perdant un temps précieux avec le siège de près de 40 villes mineures, Louis XIV néglige le cœur même des ProvincesUnies, Amsterdam. Lorsqu'il se résout à marcher sur la ville, en juin 1672, la défense hollandaise est déjà organisée et les terres environnantes sont inondées afin de préserver la ville. De même, le rejet royal des propositions de paix de la République s'avère une erreur ${ }^{39}$. La guerre s'éternise et l'espoir d'écraser définitivement la République s'évanouit, quand l'Angleterre fait défection dès 1673, et que l'évêque de Cologne échoue devant Groningue, au nord du pays.

\section{La paix de Nimègue: consécration ou victoire à la Pyrrbus?}

Louis XIV se retrouve, dès 1673 , seul face à une triple alliance qui se constitue en réaction à l'invasion française de la République. En effet, l'Espagne s'engage à

39. Les Provinces-Unies offrent, le 29 juin 1672, une forte somme d'argent et la cession à la France des Provinces de la Généralité, c'est-à-dire les provinces de Brabant et de Limbourg au sud du pays, contre le retrait des troupes. 
déclarer la guerre à la France si les pourparlers entamés à Cologne (1673) ne donnent rien. L'Empereur s'allie également aux Provinces-Unies, ainsi que le duc de Lorraine, dont le territoire est menacé par les Français. La diplomatie hollandaise vise à isoler l'ennemi français, et l'Europe s'émeut d'une politique française empreinte d'hégémonisme. L'Angleterre, notamment, se sépare de la France et conclut une paix avec la Hollande en 1674. Maintenue dans la neutralité par des subventions françaises, elle rejoint finalement le camp de la République en juillet 1678. Confronté à cette situation, Louis XIV décide, dès 1673, d'évacuer les Provinces-Unies et de concentrer ses efforts militaires sur les Pays-Bas espagnols et sur la Franche-Comté.

Le tableau qui se rapporte à la conclusion de ces alliances, situé au-dessus du passage entre le Salon de la Guerre et la Galerie, présente une autre vision des événements. Sa position (au-dessus de l'entrée) et sa datation (1672) placent la scène au début des événements. L'enchaînement des images cherche à faire croire que la France agit à la suite de la conclusion d'une alliance hostile, au lieu de l'inverse. Les Salons de la Guerre et de la Paix énoncent sans ambages que c'est le royaume français qui dicte les affaires politiques et militaires en Europe. La France domine l'un et l'autre des salons et les foudres de la guerre comme les lauriers de la paix émanent d'elle seule.

La toile représentant la conclusion de la paix, qui termine la narration picturale développée dans la Galerie, participe du même esprit. Le rôle de pacificateur revient à la France dans ce tableau, visible au-dessus de l'entrée du Salon de la Paix. En réalité, le royaume est bien contraint d'engager des négociations, à cause de l'émergence d'une alliance européenne antifrançaise. Le temps où les ProvincesUnies étaient prêtes à céder au roi une partie substantielle de leur territoire et où Louis XIV dominait la situation était alors révolu ${ }^{40}$. Sous la menace d'une intervention anglaise, furtivement évoquée dans le tableau, la paix de Nimègue est signée en août $1678^{41}$.

Toute la Galerie célèbre le triomphe de Louis XIV dans la guerre de Hollande. Cependant, cette guerre, longue et coûteuse, fut un échec. Louis XIV n’a réussi ni à briser le pouvoir économique des Provinces-Unies, ni à rayer la République de la carte politique européenne. Au contraire, une coalition dirigée par Guillaume d'Orange parvient à isoler la France et à tenir en échec ses ambitions.

40. Le fait que Guillaume d'Orange ait engagé, aux Pays-Bas espagnols, une bataille contre les Français le 14 août 1678, alors que la paix de Nimègue date de quatre jours plus tôt, montre que le Stadhouder visait à prolonger les hostilités, prétextant que la nouvelle de la signature de la paix ne lui était pas parvenue à temps. Le contraste avec l'inclination néerlandaise au début de la guerre est saisissant.

41. Le 10 août 1678 un traité est signé avec les Provinces-Unies, en septembre un deuxième traité est conclu avec l'Espagne. Finalement, en février 1679, la paix est conclue avec l'Empire. En vertu des trois traités de Nimègue, la Franche-Comté, le Cambrésis et une partie du Hainaut sont annexés par la France. Par contre, en ce qui concerne les Provinces-Unies, aucun gain n'est réalisé par la France, tout le territoire de la République étant évacué par les troupes françaises. 


\section{La construction de l'image officielle des Provinces-Unies}

Les armées de Louis XIV, invincibles à en croire la Grande Galerie, n’ont donc pas réussi à subjuguer «cette République de marchands de fromage $»^{42}$. Mais, pour comprendre comment la représentation des Provinces-Unies a joué dans la construction de l'image de Louis XIV, la «vérité effective» (selon l'expression de Machiavel) importe moins que la visée, avouée ou non, de cette représentation.

Naturellement, le principal objectif est d'encenser le roi. L'ensemble pictural de la Galerie appartient, on l'a vu, à un programme cohérent de célébration du roi, destiné aux contemporains et à la postérité. L'image de la République des ProvincesUnies est construite en fonction des besoins de Louis XIV dans un contexte d'exaltation quasi obsessionnelle du roi. La véracité de la représentation n'a dans cette perspective qu'une faible importance. Le savoir contemporain des événements en question constitue la seule contrainte d'ordre historique. Crédibilité oblige, le récit iconographique ne doit pas entrer ouvertement en conflit avec les connaissances factuelles du spectateur.

La construction de l'image du roi passe dans la Grande Galerie essentiellement par la comparaison avec la représentation des Provinces-Unies. Pour être crédible, elle fait appel à un ensemble d'idées reçues, suffisamment générales pour être acceptées, assez précises pour être reconnues. Ces idées sont habilement mises en scène en fonction des qualités du roi qui sont à démontrer. L'allégorie des ProvincesUnies et ses attributs sont révélateurs pour les notions associées à cet État.

Dans cette logique, la nature républicaine du régime néerlandais s'oppose inévitablement à la royauté et doit rappeler la supériorité de celle-ci (habits populaires opposés aux nobles attributs régaliens; positionnement inférieur dans les tableaux). Nul besoin de révéler les mauvais conseillers d'un régime bon en soi (Machiavel conseille la royauté espagnole), car le gouvernement républicain est intrinsèquement mauvais.

De même, la richesse engendrée par le commerce maritime est à l'évidence méprisable (les habits plébéiens sont recouverts par un manteau richissime, insistant sur la prétention «nouveau riche » de la République bourgeoise et commerçante). La prospérité seule n'est pas suffisante pour donner un aspect respectable à un régime assis sur le peuple. En outre, la France surclasse ces richesse et puissance maritimes : la Galerie s'attarde sur la ruine du commerce néerlandais (les ballots répandus par terre) et sur la victoire navale obtenue par l'amiral d'Estrée (les indigènes des Amérique y renvoient, ainsi que les navires du tableau «Le roi arme sur terre et sur mer $(1672) »)$.

42. Dans Versailles au siècle de Lonis XIV, op. cit., p. 11. A. de Margerie résume ainsi la situation:

Cette victoire éclatante n'est pourtant qu'un trompe-l'œil. La Franche-Comté et quelques villes et territoires du Nord et de l'Est sont bien tombés dans l'escarcelle du royaume, permettant ainsi à Vauban de renforcer sa barrière de protection de villes-forteresses. Mais le souverain du plus puissant royaume d'Europe n'est pas venu au bout de cette petite république de "marchands de fromage », comme il surnomme avec dédain la Hollande. 
Dans la même lignée se situe la dénonciation de l'ingratitude néerlandaise (l'assistance du roi trahie par la conclusion d'une alliance contre la France). Elle est destinée à contraster avec la fidélité et la droiture que l'on est en droit d'attendre d'un monarque si magnanime (secours aux amis politiques, renouvellement des alliances, lutte contre l'hérésie).

L'ensemble des métaphores employées au sujet des Provinces-Unies concourt à faire de la représentation de cette République un instrument à la gloire du monarque français. La somme de toutes les qualités attribuées aux Provinces-Unies débouche certes sur une richesse réputée, mais elle s'avère inutile contre la France, qui foudroie par l'intermédiaire de Louis XIV l'insolente République (accablée, levant vainement son bouclier; son lion en déconfiture). Dans l'iconographie de la Grande Galerie, rien ne saurait résister à la France de Louis le Grand.

\section{Conclusion}

Le programme iconographique de la Grande Galerie du château de Versailles vise à démontrer la grandeur de Louis XIV et à célébrer la prééminence de la France en Europe, établie par ses soins. Charles Le Brun a réalisé ce programme, défini par le Conseil d'en Haut même, de deux manières. Une série de petits tableaux (douze ovales et six octogonaux) insiste sur les qualités personnelles du roi (droiture, loyauté, honneur, magnanimité, générosité, foi irréprochable, etc.) et sur les bienfaits de son règne pour la France (réformes fiscales, judiciaires et économiques, mécénat, succès politiques et militaires, accroissement de sa puissance). Les douze grands décors (deux de part et d'autre de la Galerie, dix sur la voûte) développent ce thème dans le cadre d'une suite d'actes royaux illustrant la grandeur du monarque et de la France sous ses auspices. Les peintures montrent donc ce que doit être un monarque, d'une part, par une affirmation directe des qualités du prince, de l'autre, par l'application de ces qualités à un cas particulier.

L'événement mis en image à cet effet est la guerre de Hollande. Le contexte, les préparatifs, les actions militaires de cette guerre et le rétablissement triomphal de la paix sont autant de prétextes de célébrer l'action et l'envergure royales. Les Provinces-Unies constituent la puissance à laquelle se mesure Louis XIV. « Il faut dire que la distance était grande, de l'efficace petite république marchande au grand royaume encore moyenâgeux $»^{43}$.

Les raisons de la présence prépondérante de la République néerlandaise dans l'imagerie de la Galerie des Glaces sont doubles. L'importance politique de cette puissance au sein de l'Europe, d'une part, et l'aversion particulière que Louis XIV voue à son régime bourgeois et républicain, d'autre part, justifient son omniprésence. En conséquence, les Provinces-Unies sont à la fois une puissance de référence et un contre-exemple selon l'idéologie monarchique. De la sorte, la représentation de la République des Provinces-Unies contribue puissamment à la construction de l'image de Louis XIV.

43. P. Goubert, op. cit., p. 52. 
La description picturale de cet «État-étalon » est révélatrice de la perception de cette République dans l'imaginaire royal. Nation travailleuse selon le Salon de la Paix (les Hollandais s'affairent à rétablir au plus vite le commerce tandis que les autres nations accueillent la paix de manière plus festive), elle est évoquée de manière péjorative dans les autres tableaux. De par leur nature politique, républicaine, les Provinces-Unies sont jugées inférieures aux autres puissances mises en scène (positionnement dans le bas de la composition, attributs plébéiens). En outre, le pays est qualifié de prétentieux et ingrat, voire traître, dans le cycle versaillais (secourue contre l'évêque de Munster, la Hollande s'oppose cependant à la France lors de la guerre de Dévolution). La richesse, accumulée par des activités commerciales, donc contraire à la noblesse, a engendré l'insolence de ce pays. Les peintures traduisent, en résumé, une perception fort négative de la République des Provinces-Unies: puissant et insolent, cet État inférieur à la France est remis à sa place par l'action de Louis XIV.

Le contraste entre le contenu du programme iconographique de la Galerie des Glaces et le sens historique des événements est patent. Incapable d'exploiter ses succès initiaux, le roi laisse la guerre lui échapper. Isolée vers la fin du conflit, la France est contrainte de conclure la paix. «En 1678, la paix de Nimègue marque le tournant du règne $»^{44}$. La guerre de Hollande a, effectivement, durablement modifié les rapports de force sur le continent. La conjoncture politique, jusqu'à ce moment favorable à la France, s'est inversée. Désormais, une coalition européenne dirigée par Guillaume III d'Orange s'oppose aux ambitions de la France. Entre 1688 et 1713 , des guerres quasi ininterrompues sollicitent toutes les ressources de la France et épuisent le pays financièrement. Les Provinces-Unies et l'Angleterre prennent le relais de la France dans le rôle d'arbitre du jeu politique européen ${ }^{45}$. La guerre de Hollande était peut-être moins l'apothéose de Louis le Grand qu'une victoire à la Pyrrhus. Reste le rayonnement du château de Versailles et des peintures de la Grande Galerie, imités dans toute l'Europe aux XVII ${ }^{\mathrm{e}}$ et XVIII ${ }^{\mathrm{e}}$ siècles ${ }^{46}$.

Mais ce qui est plus notable encore, c'est la façon dont la représentation des Provinces-Unies dans l'iconographie versaillaise fut un instrument de la glorification de Louis XIV. Elle est fonction non pas de la véracité historique, mais des besoins du programme d'immortalisation du roi. De ce fait, le critère de l'exactitude événementielle est relégué au second plan. En somme, des idées communément reconnaissables par le public visé sont mises en image au service de l'idéologie royale.

Or, le renversement subit des alliances, consommé dès 1672, est responsable d'un décalage entre la vision largement répandue en France des Provinces-Unies,

44. A. de Margerie, op. cit., p. 5.

45. Ce d'autant que le Stadhouder néerlandais Guillaume III s'assure, lors de la seconde révolution d'Angleterre (ou la Glorious Revolution, 1688), du gouvernement de ce pays dont il est roi de 1689 jusqu'à sa mort, survenue en 1702 .

46. L'exemple le plus célèbre d'un château magniludovicien est sans doute celui de Sans-souci, édifié entre 1745 et 1747 par Georg von Knobelsdorff (1699-1753), pour Frédéric II le Grand (17121786), le « roi des soldats » en quête de reconnaissance internationale. Mais Guillaume III, l'adversaire de toujours de Louis XIV, fit également appel à des architectes français pour son palais néerlandais Het Loo. 
alliée du royaume pendant près d'un siècle, et la vision officielle imposée à grand renfort de tableaux, bas-reliefs et textes historiographiques. Centre éminent du commerce du livre et du foisonnement intellectuel de la République des Lettres, les Provinces-Unies conservent la bienveillance d'une partie importante du public savant français.

À compter de la guerre de Hollande, un écart se creuse donc entre ce qui est proféré dans la Grande Galerie et autres expressions officielles, et ce qui est perçu, à travers la lecture des feuilles et livres en provenance des imprimeurs néerlandais, dans les cabinets de travail et les bibliothèques des littéraires français. La République des Provinces-Unies reste, en dépit du changement radical du discours autorisé, un «sujet d'Étonnement» tout au long du XVIII ${ }^{\mathrm{e}}$ siècle $^{47}$.

Andreas NijenHuis, Institut Universitaire Européen de Florence.

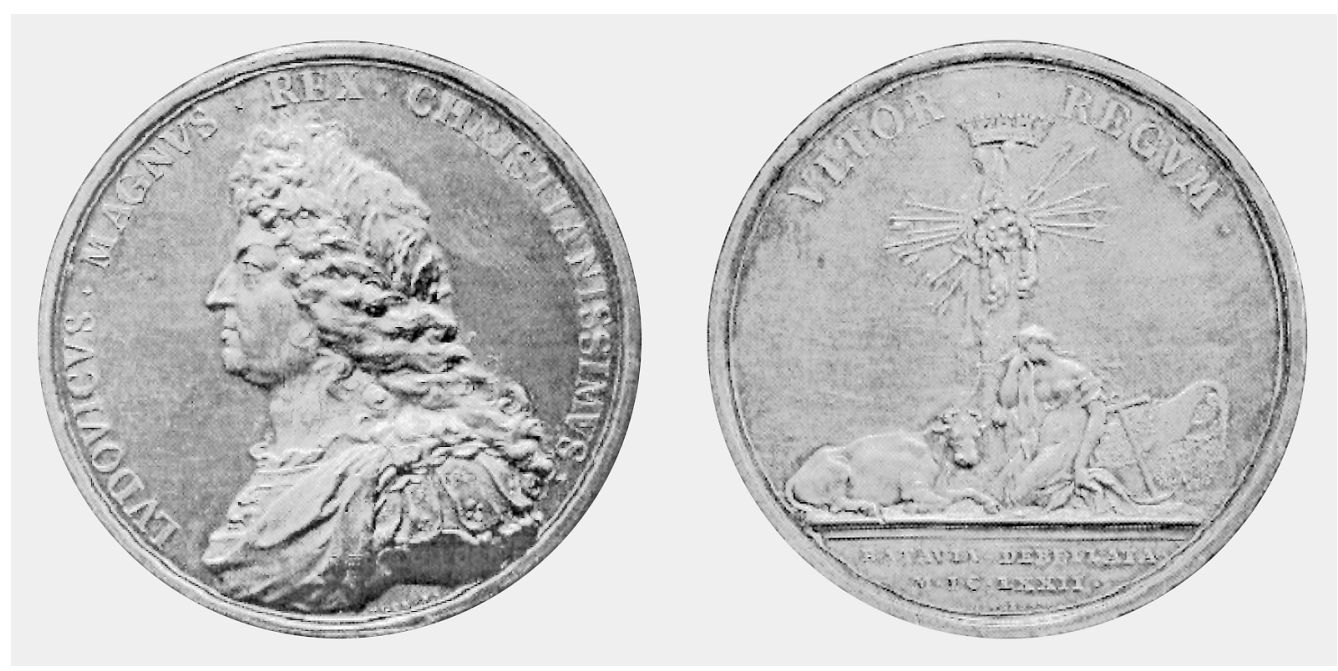

Médaille en argent (72 mm, 1672) de la main de Jean Mauger (1648-1722), portant sur la face l'inscription «LVDOVICVS.MAGNVS.REX.CHRISTIANISSIMVS », et sur le revers «VLTOR REGVM.BATAVIA.DEBELLATA./M.DC.LXXII » ${ }^{48}$

47. À titre d'exemple, le flot de récits de voyage ne tarit pas après 1666, année de l'adoption par le gouvernement français de tarifs douaniers défavorables au commerce néerlandais, premier acte ouvertement hostile à l'égard de la République. Sur un échantillon de 38 récits datés entre 1601 et 1700, 18 sont édités avant 1666, 20 après, ce qui indique, au contraire, l'accélération de la cadence de parution (9 récits dans la première moitié du siècle, 29 dans la deuxième). Les Provinces-Unies restent une étape de choix dans le parcours européen.

48. Image provenant du fonds numérique de la Bibliothèque nationale de France, Tolbiac B/P 07700293. 